\title{
Iron Level and Myelin Content in the Ventral Striatum Predict Memory Performance in the Aging Brain
}

\author{
Tineke K. Steiger, ${ }^{1,2}$ Nikolaus Weiskopf, ${ }^{3,4}$ and Nico Bunzeck ${ }^{1,2}$ \\ ${ }^{1}$ Department of Psychology, University of Lübeck, 23562 Lübeck, Germany, ${ }^{2}$ Department of Systems Neuroscience, University Medical Center Hamburg- \\ Eppendorf, 20246 Hamburg, Germany, ${ }^{3}$ Wellcome Trust Centre for Neuroimaging, UCL Institute of Neurology, University College London, WC1N 3BG \\ London, United Kingdom, and ${ }^{4}$ Department of Neurophysics, Max Planck Institute for Human Cognitive and Brain Sciences, 04103 Leipzig, Germany
}

Age-related memory impairments have been associated with structural changes in the dopaminergic system, but the underlying mechanisms remain unclear. Recent work indicates that iron accumulation might be of particular relevance. As iron accumulates, a degeneration of myelin sheaths has been observed in the elderly, but the relationship between both and their impact on memory performance in healthy elderly humans remain important open questions. To address this issue, we combined an established behavioral paradigm to test memory performance [verbal learning memory test (VLMT)] with state of the art quantitative magnetic resonance imaging techniques allowing us to quantify the degree of myelination and iron accumulation via markers of tissue microstructure in a group of young $(18-32$ years) and healthy elderly humans (55-79 years). As expected, we observed a decrease in gray matter volume and myelin, and an increase of iron in the elderly relative to the young subjects within widespread brain regions, including the basal ganglia. Furthermore, higher levels of iron within the ventral striatum were accompanied by a negative correlation between myelin and iron specific for the elderly participants. Importantly, both markers of iron and myelin (and their ratio) predicted the performance of the elderly in the VLMT. This suggests that ventral striatum iron accumulation is linked to demyelination and impairments in declarative memory. Together, our data provide novel insights into underlying microstructural mechanisms of memory decline in the elderly.

Key words: aging; iron; memory; myelin; ventral striatum

\section{Significance Statement}

Memory decline in healthy elderly is a common phenomenon, but the underlying neural mechanisms remain unclear. We used a novel approach that allowed us to combine behavior and whole-brain measures of iron, myelin, and gray matter in the participant's individual subspace to analyze structure-structure and structure-behavior interactions. We were able to show, that age-related high levels of iron are accompanied by a negative correlation of iron and myelin in the ventral striatum, which predicted individual memory performance. As such, our findings provide unprecedented insights into the basic mechanisms of memory decline in the elderly.

\section{Introduction}

Impairments in declarative long-term memory are a hallmark of healthy aging, and a convincing link to neural degeneration

\footnotetext{
Received Sept. 30, 2015; revised Dec. 4, 2015; accepted Dec. 31, 2015.

Author contributions: T.K.S. and N.B. designed research; T.K.S. performed research; T.K.S., N.W., and N.B. analyzed data; T.K.S. and N.B. wrote the paper.

This work was supported by a Hamburg state cluster of excellence (neurodapt N.B.) and the German National Academic Foundation (T.K.S.). The Wellcome Trust Centre for Neuroimaging is supported by core funding from the Wellcome Trust 0915/Z/10/Z. The research leading to these results has received funding from the European Research Council under the European Union's Seventh Framework Programme (FP7/2007-2013) / ERC Grant agreement no. 616905 (N.W.). We thank Jürgen Finsterbusch for technical support and Eva M. Bauch for help with data collection.

The Wellcome Trust Centre for Neuroimaging has an institutional research agreement with and receives support from Siemens Healthcare.

This article is freely available online through the J Neurosci Author Open Choice option.

Correspondence should be addressed to Tineke Steiger or Nico Bunzeck, Department of Psychology, University of Lübeck, Ratzeburger Allee 160, 23562 Lübeck, Germany. E-mail: tineke.steiger@uni-luebeck.de or nico.bunzeck@uni-luebeck.de.
}

across a wide range of brain regions has long been established (Hedden and Gabrieli, 2004). The underlying microstructural mechanisms, however, still remain unclear. Recent work (Daugherty et al., 2015) indicates that age-related iron accumulation in the basal ganglia might be of particular relevance. In fact, iron is mainly located in subcortical structures and rapidly increases in later life (Hallgren and Sourander, 1958; Daugherty and Raz, 2013) both during healthy and pathological aging (e.g., Parkinson's or Alzheimer's disease; Zecca et al., 2004). Importantly, as iron accumulates, a degeneration of myelin sheaths has been observed in the elderly (Peters, 2002). Whether these phys-

This is an Open Access article distributed under the terms of the Creative Commons Attribution License Creative Commons Attribution 4.0 International, which permits unrestricted use, distribution and reproduction in any medium provided that the original work is properly attributed. 
iological changes relate to each other and drive memory performance in healthy elderly humans remain open questions.

The medial temporal lobe (MTL) is essential to form new memories, and age-related structural changes within the MTL may account for a portion of the differences in memory performance (Hedden and Gabrieli, 2004; Squire et al., 2004; Persson et al., 2012). Physiologically, the MTL projects to the dopaminergic midbrain (substantia nigra/ventral tegmental area) via the nucleus accumbens and ventral pallidum (both parts of the basal ganglia), and hippocampal novelty signals may elicit dopamine release back to the MTL (Lisman and Grace, 2005; Lisman et al., 2011). In support of the hippocampus-SN/VTA model, human studies could show that age-related structural changes of the $\mathrm{SN} /$ VTA and hippocampus relate to novelty signals and memory performance (Bunzeck et al., 2007; Düzel et al., 2008), but the effects of basal ganglia iron accumulation in healthy elderly remain less clear.

At the cellular level, iron is essential for a variety of metabolic processes including the production of myelin via oligodendrocytes (Todorich et al., 2009; Mills et al., 2010). However, extensive iron accumulations may cause oxidative stress and inflammation (Zecca et al., 2004). This can have direct diminishing effects on myelin and indirect effects by injuring myelinproducing oligodendrocytes, probably by damaging their mitochondria (Haider et al., 2011; Haider, 2015). Myelin, on the other hand, covers neural axons in the form of myelin sheaths, and as such, plays a key role in transmitting electrical signals along neural circuits (Nave and Werner, 2014; Pajevic et al., 2014). Therefore, myelin is critical for many cognitive functions including learning. For instance, white matter tracts in the human brain change with learning experiences suggesting that it is highly dynamic and important for brain plasticity (Long and Corfas, 2014). From a developmental perspective, however, the vulnerability of myelin increases with age (Bartzokis, 2004) and a degeneration of myelin sheaths has been indicated during aging (Peters, 2002; Draganski et al., 2011; Callaghan et al., 2014).

Here, we combined an established behavioral paradigm to test memory performance [(verbal learning memory test (VLMT)] with state of the art quantitative magnetic resonance imaging (MRI) techniques allowing us to quantify not only gray matter volume, but also the degree of myelination and iron accumulation in a whole-brain approach. More precisely, whereas R ${ }^{*}$ (the effective transverse relaxation rate) is sensitive to tissue iron content (Péran et al., 2010), the magnetization transfer saturation (MT) is related to the exchange of magnetization between mobile water protons and protons that are bound to macromolecules as found in myelin (Wolff and Balaban, 1989). Both markers (R2* and MT) closely relate to their biochemical counterparts (myelin and iron) as shown in postmortem studies (Schmierer et al., 2004; Langkammer et al., 2010). We expected widespread age-related decreases in gray matter volume and MT (i.e., myelin) and an increase of R $2^{\star}$ (i.e., iron) within the basal ganglia. Furthermore, we hypothesized that regions with elevated $\mathrm{R} 2^{\star}$ will show a negative relationship between $\mathrm{R} 2^{\star}$ and MT due to the toxicity of accumulated iron. Finally, we expected that individual $2^{\star}$ and MT values within the elderly's basal ganglia will account for differences in memory performance.

\section{Materials and Methods}

Participants. Thirty-two healthy elderly participants were tested but one had to be excluded because of brain anomalies. The remaining 31 participants $(14$ males, mean age $=67.3$ years, $\mathrm{SD}=6.2$; age range $56-78)$ were all right-handed and had normal or corrected-to-normal vision (includ- ing color vision). None of the participants reported a history of neurologic or psychiatric disorders, or current medical problems (excluding blood pressure). All elderly (but not younger) participants successfully completed the Geriatric Depression Scale (mean GDS $=1.4, \mathrm{SD}=1.9$, GDS $\leq 5$ for all participants; GDS ranges from 0 to 15 , scores $>10$ indicates depression; Sheikh et al., 1991) and the neuropsychological battery of the Consortium to Establish a Registry for Alzheimer Disease (CERAD; Welsh et al., 1991) including the Mini Mental State Examination (MMSE; Folstein et al., 1975; mean MMSE $=29.5$, SD $=0.77$; MMSE $\geq 27$ for all participants; MMSE ranges from 0 to 30 , scores $<25$ indicate pathologies) to access mental wellbeing and cognitive integrity.

A wide age range (55-78 years) in our sample of elderly subjects was chosen for two reasons: first, structural and associated cognitive changes have been reported with an onset of $\sim 55$ years (Raz et al., 2003, 2004; Hedden and Gabrieli, 2004) and previous studies are based on a similar age range (Bunzeck et al., 2007; Düzel et al., 2008). Second, a wider age range offers more variance in the data (MT, $\mathrm{R} 2^{*}$, and behavior), which is necessary to compute correlation analyses. Note that there were no outliers in our sample of elderly subjects regarding age and brain structure.

To test for age-related structural brain differences, anatomical data of 31 healthy, right-handed young participants ( 17 males, mean age $=24.8$ years, $\mathrm{SD}=2.8$; age range $20-31$ ) were acquired. None of the participants reported a history of neurologic or psychiatric disorders (including depression), or any current medical problems. The study was approved by the local ethics committee (Medical Association Hamburg), and each subject gave informed written consent before testing.

Image acquisition. The structural data were acquired on a 3T MR system (Siemens Trio) with a standard 32-channel head coil. Whole-brain multiparameter mapping (MPM) was conducted on the basis of previous studies (Draganski et al., 2011; Callaghan et al., 2014) using multiecho 3D FLASH (fast low-angle shot) at $1 \mathrm{~mm}$ isotropic resolution with predominantly proton density (PD), MT, or T1 weighting. The weightings were determined by the choice of the repetition time (TR) and the flip angle $(\alpha)$. T1-weighted: $19 \mathrm{~ms} / 20^{\circ}$; PD- and MT-weighted: $24 \mathrm{~ms} / 6^{\circ}$ with a Gaussian-shaped RF pulse applied $2 \mathrm{kHz}$ off-resonance (4 ms duration, $220^{\circ}$ flip angle) in case of the MT-weighted acquisition. At six echo times (TE: 2.2, 4.7, 7.2, 9.7, 12, and $15 \mathrm{~ms}$ ) alternating gradient echoes were acquired. A seventh echo was acquired for the $\mathrm{PD}$-weighted acquisition at $17 \mathrm{~ms}$. To minimize off-resonance artifacts a high-readout bandwidth of $434 \mathrm{~Hz} /$ pixel was used. Speeding up data acquisition was performed using GRAPPA parallel imaging in the phase-encoded direction (anterior-posterior) with an acceleration speed factor of 2 (total scanning time of MPM protocol was $\sim 20 \mathrm{~min}$ ).

The Statistical Parametric Mapping SPM8 framework (Wellcome Trust Center for Neuroimaging, London) and customized MATLAB tools (MathWorks) were used for data processing. To obtain the R2* maps, a regression of the log signal from the PD-weighted echoes was calculated. To increase the signal-to-noise-ratio for estimation of the MT map, the set of echoes for each weighting was averaged (Helms and Dechent, 2009). The semiquantitative parameter map of MT represents the percentage loss of magnetization induced by the MT saturation pulse and was calculated as described by Helms et al. (2008a,b). We used MT instead of the commonly used MT ratio (the percentage reduction in steady-state signal) because it is implicitly corrected for non-MT-specific effects, such as spatially varying relaxation times and flip angles (Helms et al., 2008b), resulting in a more robust and higher contrast (Helms et al., 2010; Callaghan et al., 2015).

Voxel-based morphometry and voxel-based quantification. Age-related differences in gray matter volume were assessed by voxel-based morphometry (VBM; Ashburner and Friston, 2000). The MT maps where segmented into gray matter (GM), white matter (WM), and CSF within the unified segmentation approach (Ashburner and Friston, 2005). We used MT maps for segmentation, because they have a significantly improved contrast in subcortical structures, and help separating the effects of iron concentration from atrophy (Helms et al., 2009; Lorio et al., 2014). The diffeomorphic registration algorithm (DARTEL) implemented in SPM8 was used for the nonlinear transformation of the images to standard MNI (Montreal Neurological Institute) space (Ashburner, 2007). GM probability maps were scaled by the Jacobian determinants of 
the deformation field to correct for local compression and expansion and smoothed with an isotropic Gaussian kernel of $6 \mathrm{~mm}$ full-width at half-maximum (FWHM). WM volume maps were excluded because their a priori regional specificity is rather low.

To test for differences in $\mathrm{R} 2{ }^{*}$ and MT parameter, a voxel-based quantification (VBQ) analysis was used (Draganski et al., 2011; Callaghan et al., 2014), which preserves quantitative parameter values and enhances tissue specificity. Briefly, the R2* and MT were normalized into MNI space using the subjectspecific deformation fields from the DARTEL procedure but were not modulated by the Jacobian determinant. A combined tissuespecific weighting/smoothing procedure (3 mm FWHM isotropic Gaussian smoothing kernel) was used instead (Draganski et al., 2011). This method reduces the effects of residual misregistration as well as partial volume effects.

Age-related differences. To identify agerelated differences, a two-sample $t$ test implemented in SPM8 was used (young vs elderly subjects). Statistical threshold was applied at $p<0.05$ after familywise error correction (peak-voxel level) for multiple comparisons (minimum cluster size $k=25$ voxel). The effects were analyzed in WM and GM subspace separately with the use of explicit binary masks to ensure that each voxel was only analyzed in one subspace and to exclude non-brain tissue. The masks were generated as follows: averages across all subjects for each tissue class (GM, WM, CSF) were calculated using the Jacobianmodulated tissue probability maps in MNI space smoothed with a $3 \mathrm{~mm}$ isotropic kernel FWHM. Voxels were assigned to the tissue class for which their probability was maximal. If neither WM nor GM probability exceeded $20 \%$, the voxel was excluded from analysis.

Post hoc region-of-interest analyses on $M T$ and $R 2^{*}$ associations. To address the association of MT and $\mathrm{R}^{*}$ in areas with increased $\mathrm{R} 2^{*}$, the clusters of the mesolimbic system in which iron content was significantly higher in the elderly (Fig. 1c) were used as regions-of-interest (ROIs). Because there was no hypothesis about laterality, values from bilateral clusters were averaged. This resulted in two clusters for gray matter [MNI coordinates of the peak: Cluster 1: left: $x=-27, y=-7, z=1$; right: $x=$ 28, $y=-10, z=-3$; Cluster 2: left: $x=-10, y=5, z=7$; right: $x=15$, $y=-3, z=18$ ] and two clusters for white matter [MNI coordinates of the peak: Cluster 1: left: $x=-26, y=-6, z=0$; right: $x=27, y=-10$, $z=3$; Cluster 2: left: $x=-9, y=2, z=-6$; right: $x=9, y=5, z=-5$ ]. Within these ROIs, the mean MT and R2* values were calculated for each subject and subsequently tested for correlations using IBM SPSS Statistics (v21). $P$ values were corrected for multiple comparisons for each tissue separately (note, that the two tissues were considered independent because of explicit masking). This resulted in a significance threshold of $p=0.025$. For the single cluster in which a significant correlation between MT and R2* was revealed (Fig. $2 a$; ventral striatum/nucleus accumbens; MNI coordinates of the peak: left: $x=-9, y=2, z=-6$; right: $x=9, y=5, z=-5$ ), the ratio between both was calculated by dividing MT by R2*. The result was multiplied with 100 for display purposes (Fig. 2b).

Neuropsychology. To test for learning and memory performance in the elderly, we administered the VLMT (Helmstaedter et al., 2001) to all elderly (but not younger) participants as part of a wider neuropsychological assessment (results will be reported elsewhere). A similar English version, the California Verbal Learning Test, is a reliable measurement of declarative memory in aging studies (Düzel et al., 2008; Daugherty et al., 2015).
A list of 15 nonrelated items (List A) was verbally presented and the participants were asked to immediately recall as many items as possible. This procedure was repeated five times. The sum across all correctly repeated items in all five sessions is referred to as "VLMT total learning" (the ability to learn from repetition). An additional list of another 15 items was administered after the fifth session to cause interference (List B); subsequently, the participants first recalled as many items as possible from List B and then from List A. Following a 30 min delay, the participants were asked to freely recall the items from List A. The difference between the number of remembered items in learning session five and the free recall was referred to as "VLMT consolidation." Finally, this was followed by a cued recall. Here, the items of List A were presented verbally intermixed with items of List B and with semantically and phonologically similar items. Participants had to indicate whether or not an item belongs to List A. The corrected performance (correctly remembered items minus false alarms) was termed "VLMT recognition."

Regression analyses. We used whole-brain linear regression models as implemented in SPM8 to investigate the relationship between the elderly's GM, MT, and R2* maps, respectively, and their performance in the VLMT (total learning, consolidation and recognition). The different scores were used as individual regressors on the probability maps. Clusters with $>25$ voxel and a $p<0.05$ after familywise error correction at cluster-level ( $p<0.001$ uncorrected at peak-voxel level) were regarded significant. To further assess the correlations, the mean MT (or respectively $\mathrm{R} 2^{\star}$ ) values within significant clusters were plotted with SPSS Statistics. One participant had to be excluded from analysis because of poor performance in the recognition task (value deviated $>3$ SD from the group mean).

\section{Results}

In a first analysis, we used VBM to test for age-related differences in GM. Confirming previous work (Draganski et al., 2011; Cal- 

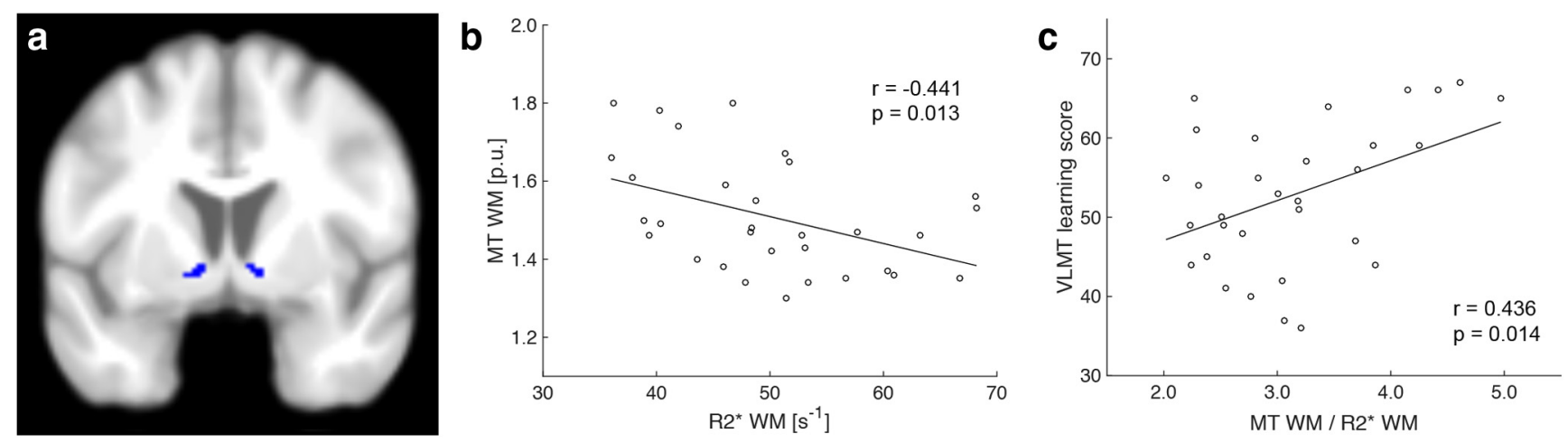

Figure 2. Relationship between MT and R2*. $\boldsymbol{a}$, One ROl within the ventral striatum (nucleus accumbens, see Material and Methods) showed increased R2* in the elderly, and ( $\boldsymbol{b})$ a negative correlation between MT and R2* . There was no such relationship in the younger subjects (see Results). c, Within this region, the ratio of MT to R2* (MT/R2* $\times 100$, for display purposes) predicted performance in the VLMT learning task.

laghan et al., 2014), we found bilaterally decreased gray matter volume in the elderly relative to the young participants in the putamen and orbitofrontal cortex (OFC), the precentral und postcentral gyri, the supplementary motor area, the left supramarginal gyrus, the right occipital cortex, the right superior temporal gyrus, the right medial frontal gyrus, as well as in the right inferior parietal gyrus (Fig. 1a).

VBQ on MT maps revealed decreases in the elderly relative to the young participants in MT saturation (indicative of myelin) within the left hippocampus, right thalamus, caudate, cerebellum, postcentral and precentral gyri, the right colliculi superior, the left occipital cortex and widespread WM tracts (Fig. 1b), in line with previous findings (Draganski et al., 2011; Callaghan et al., 2014). VBQ on R2* (indicative of iron), on the other hand, revealed increases in $\mathrm{R} 2^{*}$ in the elderly versus the young participants bilaterally in the putamen, pallidum, caudate and ventral striatum, and partly within the occipital cortex (Fig. 1c).

To further investigate the nature of higher iron levels in the elderly's basal ganglia, mean R2* and MT values for each subject were extracted in regions, where $\mathrm{R} 2^{\star}$ was significantly increased in the elderly (see Materials and Methods). A region-specific negative correlation between $\mathrm{R} 2^{*}$ and MT could be identified in the ventral striatum of the elderly $(r=-0.441, p=0.013$; Fig. $2 a, b)$, which was absent in younger participants $(r=-0.116, p=$ $0.535)$. However, a direct comparison between both correlations (Diedenhofen and Musch, 2015) did not reveal a statistically significant difference ( $p=0.09$, one-tailed), which might be due to the relatively small sample size and needs to be addressed in future studies.

To examine the relationship between memory performance and (micro)-structure, VLMT scores (learning, consolidation, recognition) of the elderly were used as covariates in whole-brain linear regression models on gray matter, $\mathrm{R} 2{ }^{*}$, and MT maps, respectively. Converging with the results above, within the ventral striatum there was a positive correlation $(p<0.05$, familywise error corrected) between VLMT learning performance and MT (Fig. 3a, $b$; MNI coordinates (peak) and size of the significant cluster: $x=-20, y=0, z=-9, k=112$ ), but a negative correlation between VLMT recognition performance and R2* (Fig. $3 c, d$; MNI coordinates (peak) and size of the significant cluster: $x=-15, y=15, z=0, k=69)$. Additionally, VLMT learning performance was predicted by the ratio of MT/R2* (Fig. $2 c$ ) as extracted from the initially identified ventral striatum region showing increased iron levels in the elderly (Fig. 2a). Importantly, none of the behavioral measures was correlated with chronological age (learning: $r=-0.196, p=0.290$; consolidation: $r=-0.032, p=0.864$; recognition: $r=-0.275, p=0.134$ ). Moreover, when adding age as a covariate in each of the correlations reported above (i.e., partial correlations), all results remain statistically significant $(p<0.05)$.

Outside the mesolimbic system, learning correlated with MT white matter and MT gray matter within the vicinity of the corpus callosum (MNI coordinates: GM: $x=-6, y=-28, z=30$; WM: $x=-4, y=-28, z=25$ ).

Finally, whole-brain regression analysis on gray matter volume and VLMT scores as covariates revealed no significant effects $(p<0.05$, familywise error corrected).

\section{Discussion}

We investigated how age-related microstructural brain differences interact and how they influence memory performance in the elderly. In line with our hypotheses (Draganski et al., 2011; Callaghan et al., 2014), we observed age-related decreases in gray matter volume and myelin, as well as increases in iron content in the elderly compared with younger participants. Furthermore, we could show that higher iron levels are associated with a regionspecific correlation of iron and myelin markers within the ventral striatum, which predicted memory performance. Finally, by analyzing behavior-structure interactions on a whole-brain basis, we found iron and myelin, but not gray matter volume, within the basal ganglia to account for individual performance differences in the elderly.

The age-related differences in the brain's macrostructure and microstructure resonate well with previous imaging studies and ex vivo histologic reports (Hallgren and Sourander, 1958; Draganski et al., 2011; Callaghan et al., 2014). Although decreases of gray matter volume in the elderly indicate macrostructural changes, their underlying mechanisms still remain unclear. They might reflect loss of neurons (Pakkenberg et al., 2003; Draganski et al., 2011), changes in synaptic density, or axonal and dendritic arborization (Terry, 2000; Hedden and Gabrieli, 2004; Esiri, 2007; Shankar, 2010). The lower MT values throughout white matter tracts and in subcortical regions in the elderly indicates less macromolecular content, mainly myelin. This probably demonstrates demyelination and dysfunctional remyelination in the aging brain (Peters, 2002; Marner et al., 2003). R2* (indicative of iron) was found to be significantly higher mainly within the elderly's basal ganglia. The reason for the accumulation of iron with age is still unclear, but some studies suggest that it may be triggered by the attempt to maintain a declining system by in- 

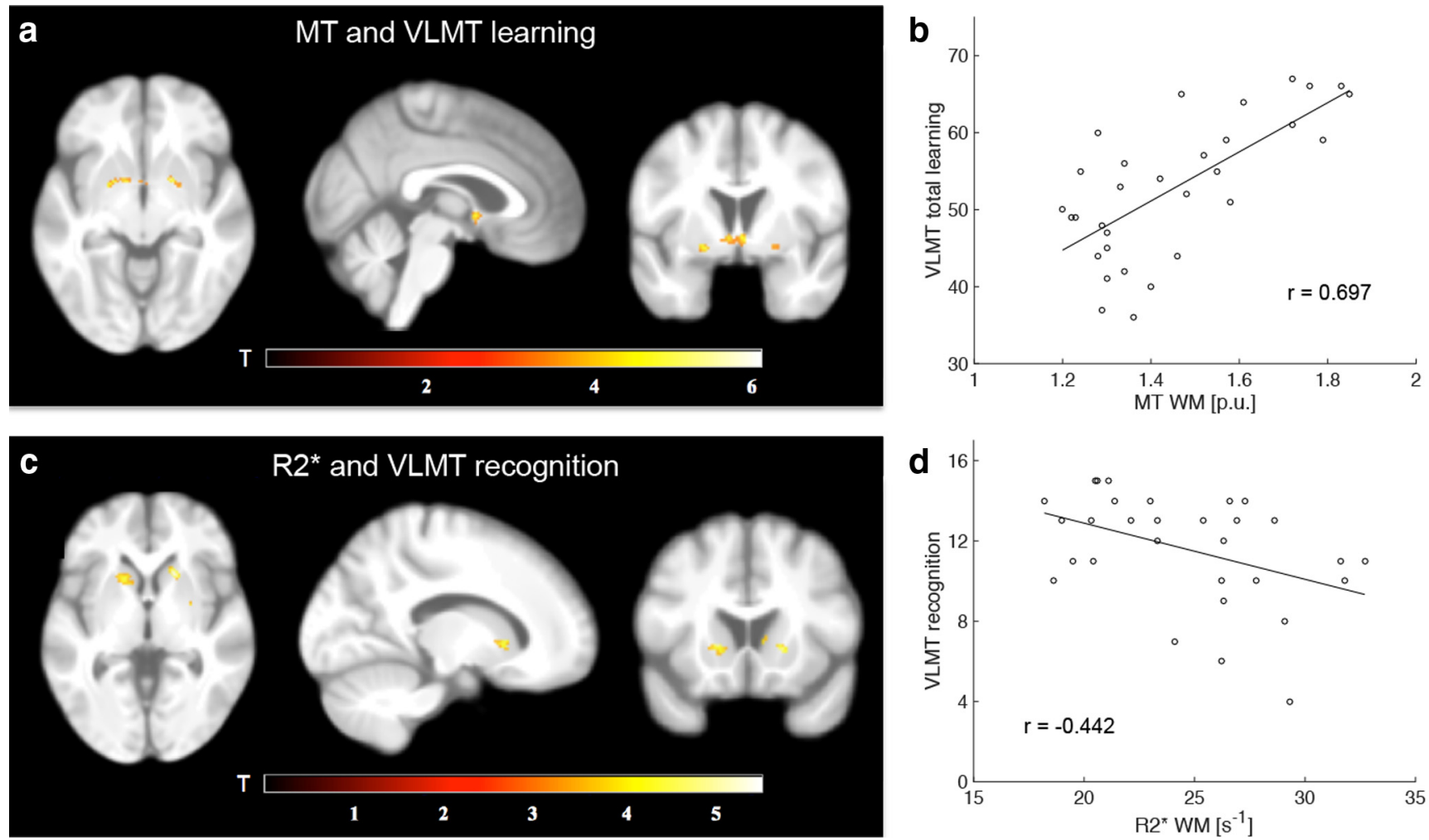

Figure 3. Relationship between microstructure and VLMT performance. $\boldsymbol{a}$, Statistical parametric maps (SPMs) showing a significant positive correlation between VLMT learning and MT in the elderly. $\boldsymbol{b}$, Correlation plot of $\boldsymbol{a}$ for illustrational purposes. $\boldsymbol{c}$, SPMs showing a significant negative correlation between VLMT recognition and R2* in the elderly. $\boldsymbol{d}$, Correlation plot of $\boldsymbol{c}$ for illustrational purposes. For display purposes, the SPMs are thresholded at $p<0.001$ (uncorrected) and superimposed on the mean T1-weighted image.

creasing metabolic processes (Bartzokis, 2004, 2011; Mills et al., 2010).

We found a negative correlation between memory performance and $\mathrm{R}^{*}$ within the ventral striatum (Fig. $3 c$ ) confirming one of our main hypotheses that basal ganglia iron accumulation has a negative impact on mnemonic functions. Functionally, the ventral striatum is part of the hippocampal-VTA-loop, which suggests that the SN/VTA and hippocampus interact to encode novel information into long-term memory. Importantly, at the downward arc of the loop there is no direct projection from the hippocampus to the dopaminergic midbrain but a polysynaptic pathway including the ventral striatum (Lisman and Grace, 2005).

Although dopamine has long been established to be critical for mnemonic functions (Jay, 2003; Morris, 2006) it is also clear that its synthesis strongly depends on the availability of iron (Zecca et al., 2004). Although a homeostatic balance between iron and dopamine levels is characteristic for the healthy brain, this relationship is inversed when iron levels are abnormally high. In fact, this pattern has been reported within the basal ganglia of patients with Parkinson's disease (Gerlach et al., 1994; Zecca et al., 2004). Therefore, our negative correlation between iron and memory performance in the elderly might be indicative of decreased dopamine because of increased iron leading to reduced memory performance. This view is further supported by animal studies showing that iron chelation reverses memory impairments that are associated with iron increases during healthy aging (de Lima et al., 2008).

Complementary to the effects of R2* (i.e., iron levels), MT (i.e., degree of myelin) within the ventral striatum correlated positively with memory performance. Physiologically, myelin ac- counts for the speed of impulse conduction (Nave and Werner, 2014), and plays an important role for the communication between brain regions, which is a critical variable for cognitive performance in general (Buzsáki and Draguhn, 2004; Pajevic et al., 2014). Importantly, learning drives myelination (Long and Corfas, 2014), and conversely, genetically modified mice, who are unable to form new myelinating oligodendrocytes failed to learn a new running strategy (McKenzie et al., 2014). Across the lifespan, the efficacy of forming new myelinating oligodendrocytes decreases (Shen et al., 2008), and thinner and shorter myelin sheaths alter transmission speed (Seidl, 2014). Our results are in line with these findings and provide in vivo evidence, that low levels of myelin within the ventral striatum are associated with lower learning performance, probably due to disturbed signal transmission within the hippocampal-VTA loop (Lisman and Grace, 2005).

Metabolically, iron is essential for the production and maintenance of myelin (Todorich et al., 2009), but imbalanced iron concentrations can trigger oxidative stress and inflammation (Zecca et al., 2004; Hare et al., 2013). Our findings of a negative relationship between $\mathrm{R} 2^{*}$ and MT in the elderly (Fig. $2 b$ ) but not younger subjects are compatible with such a view, and they demonstrate for the first time that healthy aging is not only associated with higher striatal iron levels but also with a negative correlation of iron and myelin. This suggests that high iron levels relate to demyelination in the elderly and might indicate a distorted iron to myelin homeostasis (Zecca et al., 2004). However, it may also be possible, that a myelin breakdown (e.g., due to damaged oligodendrocytes) leads to a release of iron (Izawa et al., 2010; Haider et al., 2014). In either case, as a result, the ratio between myelin and iron correlated with declarative memory perfor- 
mance, which further suggests that the striatum plays an important role in declarative memory (Lisman and Grace, 2005; Scimeca and Badre, 2012).

Finally, we would like to point out the following limitations of our study. First, R2 ${ }^{*}$ and MT are sensitive but indirect markers of iron and myelin. However, histologic evidence shows that both markers closely correspond to their biochemical counterparts (Schmierer et al., 2004; Langkammer et al., 2010). Second, we used a cross-sectional and not a longitudinal design. Therefore, the terms "increases" and "decreases" relate to group differences between young and elderly subjects rather than individual development over time.

In summary, we provide novel in vivo evidence that healthy aging is associated with higher levels of iron within the basal ganglia and a negative correlation between iron and myelin. Importantly, both markers of iron and myelin (and their ratio) predicted memory performance giving new insights into the underlying microstructural mechanism of healthy aging. From a more general point of view, our findings underline the power and sensitivity of MRI-based VBQ to investigate the effect of microstructure on behavior, which appears to be a versatile approach to disentangle healthy from pathological development in future studies.

\section{References}

Ashburner J (2007) A fast diffeomorphic image registration algorithm. Neuroimage 38:95-113. CrossRef Medline

Ashburner J, Friston KJ (2000) Voxel-based morphometry: the methods. Neuroimage 11:805-821. CrossRef Medline

Ashburner J, Friston KJ (2005) Unified segmentation. Neuroimage 26: 839-851. CrossRef Medline

Bartzokis G (2004) Age-related myelin breakdown: a developmental model of cognitive decline and Alzheimer's disease. Neurobiol Aging 25:5-18; author reply 49-62. CrossRef Medline

Bartzokis G (2011) Alzheimer's disease as homeostatic responses to agerelated myelin breakdown. Neurobiol Aging 32:1341-1371. CrossRef Medline

Bunzeck N, Schütze H, Stallforth S, Kaufmann J, Düzel S, Heinze HJ, Düzel E (2007) Mesolimbic novelty processing in older adults. Cereb Cortex 17: 2940-2948. CrossRef Medline

Buzsáki G, Draguhn A (2004) Neuronal oscillations in cortical networks. Science 304:1926-1929. CrossRef Medline

Callaghan MF, Freund P, Draganski B, Anderson E, Cappelletti M, Chowdhury R, Diedrichsen J, FitzGerald TH, Smittenaar P, Helms G, Lutti A, Weiskopf N (2014) Widespread age-related differences in the human brain microstructure revealed by quantitative magnetic resonance imaging. Neurobiol Aging 35:1862-1872. CrossRef Medline

Callaghan MF, Helms G, Lutti A, Mohammadi S, Weiskopf N (2015) A general linear relaxometry model of R1 using imaging data. Magn Reson Med 73:1309-1314. CrossRef Medline

Daugherty A, Raz N (2013) Age-related differences in iron content of subcortical nuclei observed in vivo: a meta-analysis. Neuroimage 70:113-121. CrossRef Medline

Daugherty AM, Haacke EM, Raz N (2015) Striatal iron content predicts its shrinkage and changes in verbal working memory after two years in healthy adults. J Neurosci 35:6731-6743. CrossRef Medline

de Lima MN, Dias CP, Torres JP, Dornelles A, Garcia VA, Scalco FS, Guimarães MR, Petry RC, Bromberg E, Constantino L, Budni P, DalPizzol F, Schröder N (2008) Reversion of age-related recognition memory impairment by iron chelation in rats. Neurobiol Aging 29:1052-1059. CrossRef Medline

Diedenhofen B, Musch J (2015) cocor: a comprehensive solution for the statistical comparison of correlations. PLoS One 10:e0121945. CrossRef Medline

Draganski B, Ashburner J, Hutton C, Kherif F, Frackowiak RS, Helms G, Weiskopf N (2011) Regional specificity of MRI contrast parameter changes in normal ageing revealed by voxel-based quantification (VBQ). Neuroimage 55:1423-1434. CrossRef Medline

Düzel S, Schütze H, Stallforth S, Kaufmann J, Bodammer N, Bunzeck N,
Münte TF, Lindenberger U, Heinze HJ, Düzel E (2008) A close relationship between verbal memory and SN/VTA integrity in young and older adults. Neuropsychologia 46:3042-3052. CrossRef Medline

Esiri MM (2007) Ageing and the brain. J Pathol 211:181-187. CrossRef Medline

Folstein MF, Folstein SE, McHugh PR (1975) “Mini-mental state": a practical method for grading the cognitive state of patients for the clinician. J Psychiatr Res 12:189-198. CrossRef Medline

Gerlach M, Ben-Shachar D, Riederer P, Youdim MB (1994) Altered brain metabolism of iron as a cause of neurodegenerative diseases? J Neurochem 63:793-807. Medline

Haider L (2015) Inflammation, iron, energy failure, and oxidative stress in the pathogenesis of multiple sclerosis. Oxid Med Cell Longev 2015: 725370. CrossRef Medline

Haider L, Fischer MT, Frischer JM, Bauer J, Höftberger R, Botond G, Esterbauer H, Binder CJ, Witztum JL, Lassmann H (2011) Oxidative damage in multiple sclerosis lesions. Brain 134:1914-1924. CrossRef Medline

Haider L, Simeonidou C, Steinberger G, Hametner S, Grigoriadis N, Deretzi G, Kovacs GG, Kutzelnigg A, Lassmann H, Frischer JM (2014) Multiple sclerosis deep grey matter: the relation between demyelination, neurodegeneration, inflammation and iron. J Neurol Neurosurg Psychiatry 85: 1386-1395. CrossRef Medline

Hallgren B, Sourander P (1958) The effect of age on the non-haemin iron in the human brain. J Neurochem 3:41-51. CrossRef Medline

Hare D, Ayton S, Bush A, Lei P (2013) A delicate balance: iron metabolism and diseases of the brain. Front Aging Neurosci 5:34. CrossRef Medline

Hedden T, Gabrieli JD (2004) Insights into the ageing mind: a view from cognitive neuroscience. Nat Rev Neurosci 5:87-96. CrossRef Medline

Helms G, Dechent P (2009) Increased SNR and reduced distortions by averaging multiple gradient echo signals in 3D FLASH imaging of the human brain at 3T. J Magn Reson Imaging JMRI 29:198-204. CrossRef Medline

Helms G, Dathe H, Dechent P (2008a) Quantitative FLASH MRI at 3T using a rational approximation of the Ernst equation. Magn Reson Med 59: 667-672. CrossRef Medline

Helms G, Dathe H, Kallenberg K, Dechent P (2008b) High-resolution maps of magnetization transfer with inherent correction for RF inhomogeneity and T1 relaxation obtained from 3D FLASH MRI. Magn Reson Med 60:1396-1407. CrossRef Medline

Helms G, Draganski B, Frackowiak R, Ashburner J, Weiskopf N (2009) Improved segmentation of deep brain grey matter structures using magnetization transfer (MT) parameter maps. Neuroimage 47:194-198. CrossRef Medline

Helms G, Dathe H, Dechent P (2010) Modeling the influence of TR and excitation flip angle on the magnetization transfer ratio (MTR) in human brain obtained from 3D spoiled gradient echo MRI. Magn Reson Med 64:177-185. CrossRef Medline

Helmstaedter C, Lendt M, Lux S (2001) VLMT Verbaler Lern: und Merkfähigkeitstest. Göttingen: Beltz Test $\mathrm{GmbH}$.

Izawa T, Yamate J, Franklin RJ, Kuwamura M (2010) Abnormal iron accumulation is involved in the pathogenesis of the demyelinating $d m y$ rat but not in the hypomyelinating $m v$ rat. Brain Res 1349:105-114. CrossRef Medline

Jay TM (2003) Dopamine: a potential substrate for synaptic plasticity and memory mechanisms. Prog Neurobiol 69:375-390. CrossRef Medline

Langkammer C, Krebs N, Goessler W, Scheurer E, Ebner F, Yen K, Fazekas F, Ropele S (2010) Quantitative MR imaging of brain iron: a postmortem validation study. Radiology 257:455-462. CrossRef Medline

Lisman JE, Grace AA (2005) The hippocampal-VTA loop: controlling the entry of information into long-term memory. Neuron 46:703-713. CrossRef Medline

Lisman J, Grace AA, Duzel E (2011) A neoHebbian framework for episodic memory: role of dopamine-dependent late LTP. Trends Neurosci 34: 536-547. CrossRef Medline

Long P, Corfas G (2014) To learn is to myelinate. Science 346:298-299. CrossRef Medline

Lorio S, Lutti A, Kherif F, Ruef A, Dukart J, Chowdhury R, Frackowiak RS, Ashburner J, Helms G, Weiskopf N, Draganski B (2014) Disentangling in vivo the effects of iron content and atrophy on the ageing human brain. Neuroimage 103:280-289. CrossRef Medline

Marner L, Nyengaard JR, Tang Y, Pakkenberg B (2003) Marked loss of myelinated nerve fibers in the human brain with age. J Comp Neurol 462: 144-152. CrossRef Medline 
McKenzie IA, Ohayon D, Li H, de Faria JP, Emery B, Tohyama K, Richardson WD (2014) Motor skill learning requires active central myelination. Science 346:318-322. CrossRef Medline

Mills E, Dong XP, Wang F, Xu H (2010) Mechanisms of brain iron transport: insight into neurodegeneration and CNS disorders. Future Med Chem 2:51-64. CrossRef Medline

Morris RG (2006) Elements of a neurobiological theory of hippocampal function: the role of synaptic plasticity, synaptic tagging and schemas. Eur J Neurosci 23:2829-2846. CrossRef Medline

Nave KA, Werner HB (2014) Myelination of the nervous system: mechanisms and functions. Annu Rev Cell Dev Biol 30:503-533. CrossRef Medline

Pajevic S, Basser PJ, Fields RD (2014) Role of myelin plasticity in oscillations and synchrony of neuronal activity. Neuroscience 276:135-147. CrossRef Medline

Pakkenberg B, Pelvig D, Marner L, Bundgaard MJ, Gundersen HJ, Nyengaard JR, Regeur L (2003) Aging and the human neocortex. Exp Gerontol 38: 95-99. CrossRef Medline

Péran P, Cherubini A, Assogna F, Piras F, Quattrocchi C, Peppe A, Celsis P, Rascol O, Démonet JF, Stefani A, Pierantozzi M, Pontieri FE, Caltagirone C, Spalletta G, Sabatini U (2010) Magnetic resonance imaging markers of Parkinson's disease nigrostriatal signature. Brain 133:3423-3433. CrossRef Medline

Persson J, Pudas S, Lind J, Kauppi K, Nilsson LG, Nyberg L (2012) Longitudinal structure-function correlates in elderly reveal MTL dysfunction with cognitive decline. Cereb Cortex 22:2297-2304. CrossRef Medline

Peters A (2002) The effects of normal aging on myelin and nerve fibers: a review. J Neurocytol 31:581-593. CrossRef Medline

Raz N, Rodrigue KM, Kennedy KM, Head D, Gunning-Dixon F, Acker JD (2003) Differential aging of the human striatum: longitudinal evidence. Am J Neuroradiol 24:1849-1856. Medline

Raz N, Rodrigue KM, Head D, Kennedy KM, Acker JD (2004) Differential aging of the medial temporal lobe: a study of a five-year change. Neurology 62:433-438. CrossRef Medline
Schmierer K, Scaravilli F, Altmann DR, Barker GJ, Miller DH (2004) Magnetization transfer ratio and myelin in postmortem multiple sclerosis brain. Ann Neurol 56:407-415. CrossRef Medline

Scimeca JM, Badre D (2012) Striatal contributions to declarative memory retrieval. Neuron 75:380-392. CrossRef Medline

Seidl AH (2014) Regulation of conduction time along axons. Neuroscience 276:126-134. CrossRef Medline

Shankar SK (2010) Biology of aging brain. Indian J Pathol Microbiol 53: 595-604. CrossRef Medline

Sheikh JI, Yesavage JA, Brooks JO 3rd, Friedman L, Gratzinger P, Hill RD, Zadeik A, Crook T (1991) Proposed factor structure of the geriatric depression scale. Int Psychogeriatr 3:23-28. CrossRef Medline

Shen S, Sandoval J, Swiss VA, Li J, Dupree J, Franklin RJ, Casaccia-Bonnefil P (2008) Age-dependent epigenetic control of differentiation inhibitors is critical for remyelination efficiency. Nat Neurosci 11:1024-1034. CrossRef Medline

Squire LR, Stark CE, Clark RE (2004) The medial temporal lobe. Annu Rev Neurosci 27:279-306. CrossRef Medline

Terry RD (2000) Cell death or synaptic loss in Alzheimer disease. J Neuropathol Exp Neurol 59:1118-1119. CrossRef Medline

Todorich B, Pasquini JM, Garcia CI, Paez PM, Connor JR (2009) Oligodendrocytes and myelination: the role of iron. Glia 57:467-478. CrossRef Medline

Welsh K, Butters N, Hughes J, Mohs R, Heyman A (1991) Detection of abnormal memory decline in mild cases of Alzheimer's disease using CERAD neuropsychological measures. Arch Neurol 48:278-281. CrossRef Medline

Wolff SD, Balaban RS (1989) Magnetization transfer contrast (MTC) and tissue water proton relaxation in vivo. Magn Reson Med 10:135-144. CrossRef Medline

Zecca L, Youdim MB, Riederer P, Connor JR, Crichton RR (2004) Iron, brain ageing and neurodegenerative disorders. Nat Rev Neurosci 5: 863-873. CrossRef Medline 